\title{
A Literature Survey on Various Factors in Dynamic Cellular Manufacturing System
}

\author{
S.M.Saleemuddin ${ }^{1}$, Sanjeev Reddy K.Hudgikar ${ }^{2}$ \\ ${ }^{1}$ Faculty of Mechanical Engineering, AITS, Rajampet, KAdapa (Dist), AP \\ ${ }_{2}^{2}$ Principal, Lingarajappa Engineering College, Bidar, Karnataka
}

\begin{abstract}
Cellular manufacturing system deals with grouping of machines and parts into machine cells and part families with their compatibility. Reduction in part life cycle and variation in product mix and demand creates dynamic condition in the manufacturing systems. In previous work manufacturing companies has faces a lot of problems in meeting the customer requirement in dynamic conditions. Cellular Manufacturing System is a type of manufacturing system which tries to create a flexibility of job type and also productivity in shop floor. Now a day's Dynamic cellular manufacturing system becomes the emerging topic and attracts of lot of attention at different times intervals. This paper gives the brief review about the work which was focused on all published paper on this subject.
\end{abstract}

Keywords: Cellular manufacturing system, Meta-Heuristic

\section{Introduction}

A manufacturing system in which machines and tools are arranged to facilitate small lot, continuous flow production. In a manufacturing cell, all operations are necessary to produce a component or sub assembly are performed in close proximity, often times in a U-shaped layout, thus allowing for quick feedback between operations when problems and other issues arise. Workers in manufacturing cells are typically cross trained and able to perform multiple tasks as needed.

In Conventional systems, similar machines are grouped together (e.g. lathes, mills, drills, presses, painting, cleaning, etc.). These layouts are more robust to machine breakdowns, have common jigs and fixtures in the same area, and support high levels of demarcation. In cellular manufacturing systems machines are grouped into machine cells and parts into part families are produced, which provides a distinct advantage in that material flow is significantly improved, which reduces the distance travelled by materials, inventory, people which increases the overall lead times. The main advantages of analysis of a proper manufacturing process lie not only in increased production and delivery, but also in improved product quality, increased product flexibility and enhanced overall productivity

The overall process of designing CMS involves the following four generic phases:

1. Cell formation: involves grouping of machines which can operate on a product family with little or no inter-cell movement of the products.

2. Group layout: includes layout of machines within each cell (intra-cell layout), and layout of cells with respect to one another (inter-cell layout).

3. Group scheduling: In this parts are to be scheduled for production

4. Resource allocation: Based on the production allocation should be done i.e., assignment of tools, manpower, materials, and other resources

\section{Literature Survey}

There are two types of manner for cellular manufacturing system which are static and dynamic condition. A Static Condition in Dynamic Cellular Manufacturing System is not considered when part mix and demand is change, so we considered Dynamic Condition. A number of papers were published on this area and a few were collected from the recent years.

\section{CANADA}

- Shahram Sharafi proposed a closed job shop, in which a fixed number of products are produced on a repetitive basis, when there are significant sequence dependent on setup times, costs involved, cell formation (CF) problem considered to minimize the production cost. Setup time reduction in CMS has gained little to modest attention in the literature. [1]

\section{INDIA}

- Kamal Deep et al., In this work puts emphasize on the production flexibility (production/subcontracting part operation) to satisfy the product demand requirement in different period segments of planning horizon considering production capacity shortage and/or sudden machine breakdown. The proposed model 
simultaneously generates machine cells and part families and selects the optimum process route instead of the user specifying predetermined routes. Conventional optimization method for the optimal cell formation problem requires substantial amount of time and memory space. [2]

- Madhusudan Pillai et al., : Two types of cellular system designs are possible for a production environment consisting of dynamic part population: adaptive and robust layouts. Cellular manufacturing system designs in literature show that some of the cells formed have large number of machines compared to other cells. This paper is mainly concerned with developing suitable mathematical model so that more or less same number of machines in every cell is possible for the adaptive and robust designs. [3].

- V.Anbumalar et al., A framework is proposed that creates a multi-period cellular layout plan including cell redesign where appropriate. The framework is illustrated using a two stage procedure based on the generalized machine assignment problem and dynamic programming. This framework is conceptually compared to virtual cell manufacturing, which is useful when there is uncertainty in demand rather than anticipated changes in demand. [4]

- Anbumalar $\mathbf{V}$ et al., In cellular manufacturing, Cell formation, static layouts, dynamic layouts are the prime areas for achieving the optimal cellular layout for any problems. In this paper it is decided to review the recent research work in this particular area and to project the effective ways of solving the cellular layout problems by comparing with the standard performance measures. [5]

- Kamal Deep et al., proposed a model incorporates machine cell configuration design problem bridged with the machines allocation problem, the dynamic production problem and the part routing problem. Multiple process plans for each part and alternatives process routes for each of those plans are considered. The robust cell design is considered based on the selection of best process routing from the user specified multiple routings for each part type considering average product demand during the planning horizon. The dynamic part demand can be satisfied from internal production having limited capacity and/or through subcontracting part operation without affecting the machine cell configuration in successive period segments of the planning horizon.. [6]

\section{IRAN}

- Rafiee $\mathbf{K}$ et al.,: In contrast, dynamic situation which is more realistic concentrated on a multi-period planning horizon where the demand and product mix will change over the periods; therefore, optimum cell configuration in one period may not be suitable for another period [7]

- Seyed Vahid Daei Niaki et al., : The aim of the proposed model is to reduce the cost of inter and intra-cell movement, machine and reconfiguration costs, setup costs, production planning costs (holding, backorder and subcontracting costs) and workers hiring, firing, training and salary costs, as well as minimizing summation of machines idle times as a second objective.[8]

- Hiwa Farughi et al., : A robust optimization of a bi-objective mathematical model in a dynamic cell formation problem considering that labor utilization with uncertain data is carried out. The robust approach is used to reduce the effects of fluctuations of the uncertain parameters with regard to all the possible future scenarios. The first objective function seeks to minimize relevant costs of the problem including machine procurement and relocation costs, machine variable cost, inter-cell movement and intra-cell movement costs, overtime cost and labor shifting cost between cells, machine maintenance cost, inventory, holding part cost. The second objective function seeks to minimize total man-hour deviations between cells or indeed labor utilization of the modeled. [9]

- Présentée devant L: A bi-objective model which is to make a trade-off between social (job opportunity, potential machine hazards, etc.) and economic (various costs related to cell formation) criteria and to get closer in real-life situations, some parameters such as demand, machine-related costs and time capacity of the machines are considered as uncertain. To solve this problem, a robust optimization method is applied to cope with this uncertainty.[10]

- Vahid Majazi Dalfard: The presented model is NP-hard. A new strategy known as simulated annealing embedded in branch and cut was developed to solve the problem. In comparison with standard branch and cut, results of solving different problems showed speed and efficiency of simulated annealing embedded in branch and cut.[11]

- R. Kia et al.,: A novel aspect of this model is concurrently making the CF and GL decisions in a dynamic environment. The proposed model integrating the CF and GL decisions can be used by researchers and practitioners to design GL in practical and dynamic cell formation problems. Another compromising aspect of this model is the utilization of multi-rows layout to locate machines in the cells configured with flexible shapes. Such a DCMS model with an extensive coverage of important manufacturing features has not been proposed before and incorporates several design features including alternate process routings, operation 
sequence, processing time, production volume of parts, purchasing machine, duplicate machines, machine capacity, lot splitting, intra-cell layout, inter-cell layout, multi-rows layout of equal area facilities and flexible reconfiguration. The objective of the integrated model is to minimize the total costs of intra and inter-cell material handling, machine relocation, purchasing new machines, machine overhead and machine processing. [12]

- N. Aghajani-Delavar et al., creates a new mathematical model for integrated dynamic cellular manufacturing systems and production planning that minimizes machine purchasing, intra-cell material handling, cell reconfiguration and setup costs. The proposed model forms the manufacturing cells and determines the quantity of machine and movements during each period of time. [13]

- Esmaeil Mehdizadeh et al., Proposed A Comprehensive model includes dynamic system reconfiguration, multi period production planning, operation sequence, alternative process plans for part types, machine and worker flexibility, duplicate machines, machine capacity, available time of workers and worker assignment. The main objective of the proposed model is to reduce the inter and intra-cell movement costs, machine and reconfiguration costs, setup costs, production planning costs (holding, backorder and subcontracting costs) and workers hiring, firing, training and salary costs, as well as minimizing summation of machines idle times as a second objective. Due to NP-hardness of the problem, a recent and efficient meta-heuristic algorithm namely multi-objective vibration damping optimization MOVDO) is designed for finding Paretooptimal frontier. [14]

\section{Malaysia}

- Aidin Delgoshaei et al., proposed a "Cell load variation is considered a significant shortcoming in scheduling of cellular manufacturing systems. In this article, a new method is proposed for scheduling dynamic cellular manufacturing systems in the presence of bottleneck and parallel machines.. A new method is proposed for scheduling dynamic cellular manufacturing systems in the presence of bottleneck, parallel machines and cell load variation during the process. An analysis is to be done on the results in consideration of various factors, and control charts are used on machine-load variation.An increase in product uncertainty level causes the loading level of each cell to vary the results in the development of "complex dummy sub-cells". [15]

\section{Turkey}

- Adil Baykasog`lu et al.,: Constraint programming is a new approach to combinatorial optimization and provides a rich language to represent complex constraints easily. However, the cell formation problems are well suited to be solved by constraint programming approach since the problem has many constraints such as part-machine requirements, availabilities in the system in terms of capacity, machine and worker abilities. In this study, the cell formation problem is modelled using machine, part processing and worker flexibilities via resource element-based representation. Resource elements define the processing requirements of parts and processing capabilities of machines and workers, which are resource-independent capability units. [16]

UK

- Papaioannou G et al., : A static environment is related to the traditional CMS where no changes in the demand are taken into account whereas in dynamic environment, the part demand volume and part mix will change. Most previous articles considered the CMS under the static condition and just formed cells in a single-time period.[17]

USA

- Elin m. Wicks et al.,: A new formulation of the part family/machine cell formation problem that addresses the dynamic nature of the production environment by considering a multi-period forecast of product mix and demand during the formation of part families and machine cells. The goal of the multi-period formulation is to obtain a cellular design that continues to perform well with respect to the design objectives as the part population changes with time.[18]

\section{Conclusions}

Cellular manufacturing system is one of the main applications of group technology which gains a lot of attentions during the years. This paper gives a lot of information about multiple factors like (production planning (optimum production policy like production, inventory and subcontracting quantity level) operation sequence, alternative process plans, machine and worker flexibility, machine capacity, available time of workers, worker assignment and minimizing inter and intra cell movement etc) )working in dynamic cellular manufacturing system. In addition, due to short life cycle which leads to changes in demand and product mix over the periods, concentrating on dynamic situation for manufacturing system is closer to the reality than the static situation. Due to this most of the researchers concentrating the dynamic cellular manufacturing system 
rather than static. So Dynamic Environment is a emerging topic in cellular manufacturing system. By focusing on dynamic cellular manufacturing system a brief literature was collected from the recent papers which were published. The work can be further extended in future incorporating production data like product sequence, machine capacity, lot size of parts, layout considerations and material handling systems enhancing it to a more generalized in dynamic environment.

\section{References}

[1] Shahram Sharafi (2012). Operation-Level Sequence-Dependent Setup Time Reduction In Dynamic Cellular Manufacturing Systems.Phd Thesis.

[2] KAMAL DEEP et al., (2016). Dynamic cellular manufacturing system design considering alternative routing and part operation trade-off using simulated annealing based genetic algorithm. Indian Academy sciences, Vol. 41, No. 9, September 2016, pp. $1063-$ 1079.

[3] Madhu Sudan Pillai et al.,(2011). Analysis of robust and adaptive designs for dynamic part population.Research Gate

[4] V.Anbumalar, R. Mayandy, D.Sivasankar,(2015). Dynamic Cellular Manufacturing under Multi-period Planning Horizons. International Journal of Innovative Research in Science, Engineering and Technology, Volume 4, Special Issue 3, March 2015

[5] Anbumalar, V et al., (2015). Methods For Solving Cell Formation, Static Layout And Dynamic Layout Cellular Manufacturing System Problems: A Review, Asian Journal of Science and Technology,Vol.06, Issue, 12, pp.2107-2112, December, 2015.

[6] Kamal Deep et al., (2015). Design of robust cellular manufacturing system for dynamic part population considering multiple processing routes using genetic algorithm, Journal of Manufacturing Systems 35 (2015) 155-163.

[7] Rafiee, K., Rabbani, M., Rafiei, H., \& Rahimi-Vahed, A. (2011). A new approach towards integrated cell formation and inventory lot sizing in an unreliable cellular manufacturing system, J. Applied Mathematical Modelling, 35(4), 1810-1819.

[8] Seyed Vahid Daei Niakia, Esmaeil Mehdizadeha, Reza Tavakkoli-Moghaddamb (2011). A mathematical model for dynamic cellular manufacturing systems with production planning and labor assignment, 025-0502.

[9] Hiwa Farughia* and Sobhan Mostafayi (2016). Robust Optimization Approach for Design for a Dynamic Cell Formation Considering Labor Utilization: Bi-objective Mathematical Model, International Journal of Supply and Operations Management, May 2016, Volume 3, Issue 1, pp. 1143-1167.

[10] Présentée devant, (2015). Design and Configuration of Sustainable Dynamic Cellular Manufacturing Systems, 2015 ISAL0123.

[11] Majazi Dalfard V. (2013). New mathematical model for problem of dynamic cell formation based on number and average length of intra and intercellular movements. J. Applied Mathematical Modelling, 37(4).

[12] R. Kia et al.,(2012). Solving a group layout design model of a dynamic cellular manufacturing system with alternative process routings, lot splitting and flexible reconfiguration by simulated annealing, Research, Volume, November 2012, Pages 2642-2658.

[13] N. Aghajani-Delavar et al., (2015). Design of a New Mathematical Model for Integrated Dynamic Cellular Manufacturing Systems and Production Planning, International Journal of Engineering, Vol. 28, No. 5, (May 2015) 746-754.

[14] Esmaeil Mehdizadeh et al., (2016). A vibration damping optimization algorithm for solving a new multi-objective dynamic cell formation problem with workers training, Computers \& Industrial Engineering 101 (2016) 35-52.

[15] Aidin Delgoshaei, Mohd Khairol Mohd Ariffin, Btht Hang Tuah Bin Baharudin and Zulkiflle Leman (2015). A new method for decreasing cell-load variation in dynamic cellular manufacturing systems. International Journal of Industrial Engineering Computations, 7 (2016) 83-110.

[16] Adil Baykasog -1 et al.,(2016). Manufacturing cell formation with flexible processing capabilities and worker assignment: Comparison of constraint programming and integer programming approaches, Institute of Mechanical Engineers, Published by SAGE.

[17] Papaioannou, G.and Wilson, J.M. (2010). The evoultion of cell formation problem methodologies based on recent studies (19972008): Review and directions for future research. European Journal of Operational Research, 206(3), 509-521.

[18] Wicks and Reasor, (1999). Designing cellular manufacturing systems with dynamic part populations, IIE Transactions (1999) 31 , $11-20$. 